\title{
Efficacy and safety of upadacitinib over 84 weeks in Japanese patients with rheumatoid arthritis (SELECT-SUNRISE)
}

Hideto Kameda ${ }^{1 *} \mathbb{D}$, Tsutomu Takeuchi ${ }^{2}$, Kunihiro Yamaoka ${ }^{3}$, Motohiro Oribe $^{4}$, Mitsuhiro Kawano ${ }^{5}$, Masayuki Yokoyama ${ }^{6}$, Aileen L. Pangan ${ }^{7}, Y$ Ku Konishi ${ }^{6}$, Sebastian Meerwein ${ }^{8}$ and Yoshiya Tanaka ${ }^{9}$

\begin{abstract}
Background: The objective of the study was to evaluate the efficacy and safety of upadacitinib over 84 weeks in Japanese patients with active rheumatoid arthritis (RA) and an inadequate response to conventional synthetic disease-modifying anti-rheumatic drugs.

Methods: All patients completing a 12-week, randomized, double-blind treatment period entered a blinded extension and continued upadacitinib 7.5, 15, or $30 \mathrm{mg}$ once daily (QD), or were switched from placebo to upadacitinib 7.5, 15, or $30 \mathrm{mg}$ QD. Efficacy and safety were assessed over 84 weeks.

Results: Of 197 randomized patients, 187 (94.9\%) completed the 12-week period and entered the blinded extension; 152 (77.2\%) patients were ongoing at week 84. At week 84, the proportions of patients achieving a 20\% improvement in American College of Rheumatology criteria (ACR20) were 85.7\%, 77.6\%, and 58.0\% with continued upadacitinib 7.5, 15, and $30 \mathrm{mg}$, respectively (nonresponder imputation), and were similar in patients who had switched from placebo. Favorable response rates were also observed for more stringent measures of response (ACR50/70) and remission (defined by the Disease Activity Score of 28 joints with C-reactive protein, Clinical Disease Activity Index, or Simplified Disease Activity Index). The $15 \mathrm{mg}$ and $30 \mathrm{mg}$ doses of upadacitinib were associated with more rapid and numerically higher initial responses for some measures of disease activity and remission compared with the $7.5 \mathrm{mg}$ dose. Rates of adverse events, infection, opportunistic infection, serious infection, and herpes zoster were lower with upadacitinib 7.5 and $15 \mathrm{mg}$ versus $30 \mathrm{mg}$.
\end{abstract}

Conclusions: Upadacitinib demonstrated sustained efficacy and was well tolerated over 84 weeks in Japanese patients with RA, with upadacitinib $15 \mathrm{mg}$ offering the most favorable benefit-risk profile.

Trial registration: ClinicalTrials.gov NCT02720523. Registered on March 22, 2016.

Keywords: Janus kinase inhibitor, Japanese, Rheumatoid arthritis, Upadacitinib

\footnotetext{
* Correspondence: hideto.kameda@med.toho-u.ac.jp

'Division of Rheumatology, Department of Internal Medicine, Faculty of Medicine, Toho University, 2-22-36, Ohashi, Meguro-ku, Tokyo 153-8515, Japan

Full list of author information is available at the end of the article
}

(c) The Author(s). 2021 Open Access This article is licensed under a Creative Commons Attribution 4.0 International License, which permits use, sharing, adaptation, distribution and reproduction in any medium or format, as long as you give appropriate credit to the original author(s) and the source, provide a link to the Creative Commons licence, and indicate if changes were made. The images or other third party material in this article are included in the article's Creative Commons licence, unless indicated otherwise in a credit line to the material. If material is not included in the article's Creative Commons licence and your intended use is not permitted by statutory regulation or exceeds the permitted use, you will need to obtain permission directly from the copyright holder. To view a copy of this licence, visit http://creativecommons.org/licenses/by/4.0/. The Creative Commons Public Domain Dedication waiver (http://creativecommons.org/publicdomain/zero/1.0/) applies to the data made available in this article, unless otherwise stated in a credit line to the data. 


\section{Background}

The Janus kinase (JAK) family (JAK1, 2, 3, and tyrosine kinase 2 [TYK2]) are important mediators of multiple cytokine-signaling pathways involved in normal cellular processes, as well as in the pathogenesis of rheumatoid arthritis (RA) and other immune-mediated inflammatory diseases [1-3]. Orally administered JAK inhibitors belong to the class of targeted synthetic disease-modifying anti-rheumatic drugs (DMARDs) and are currently recommended globally as treatment options for patients with RA who have moderate or high disease activity despite conventional synthetic DMARD (csDMARD) therapy, or in patients who have failed treatment with a biologic DMARD (bDMARD) [4-6]. Currently, 3 JAK inhibitors are approved for the treatment of RA in the USA, EU, and Japan: tofacitinib, baricitinib, and most recently upadacitinib. These treatments have shown efficacy and an acceptable safety profile in global populations in the phase 3 clinical trial programs, as well as in trials run specifically in Japanese patients with RA, although higher rates of herpes zoster have been reported in Japan and other Asian countries versus the global population [7-11].

Upadacitinib (ABT-494) is an oral JAK inhibitor engineered for greater selectivity toward JAK1 versus JAK2, JAK3, and TYK2 [12] and is approved at the dose of 15 $\mathrm{mg}$ once daily (QD) in the USA and EU, and at the doses of $7.5 \mathrm{mg}$ QD and $15 \mathrm{mg}$ QD in Japan. Upadacitinib was efficacious and well tolerated in both global phase $2[13,14]$ and phase 3 studies [15-18]. In the SELECT-SUNRISE study, upadacitinib in combination with csDMARDs improved outcomes at week 12 versus placebo in Japanese patients with an inadequate response to csDMARDs [11]. Here we report the results of the long-term extension phase of the SELECT-SUNRISE study, with efficacy and safety data up to week 84 .

\section{Methods}

\section{Study design and patients}

SELECT-SUNRISE (NCT02720523) was a phase 2b/3, multicenter study that included 2 periods (Supplementary Figure 1 [11]). In period 1, Japanese patients with moderately to severely active RA and an inadequate response to csDMARDs, and on a stable dose of csDMARDs, were randomized to receive upadacitinib $7.5 \mathrm{mg}, 15 \mathrm{mg}$, or $30 \mathrm{mg}$ QD, or placebo for 12 weeks during a double-blind period. All patients who completed period 1 entered the blinded extension at 12 weeks, in which they continued with upadacitinib 7.5 $\mathrm{mg}, 15 \mathrm{mg}$, or $30 \mathrm{mg}$ QD or were switched from placebo to upadacitinib $7.5 \mathrm{mg}, 15 \mathrm{mg}$, or $30 \mathrm{mg}$ QD according to prespecified randomization assignments.

In patients who failed to achieve Clinical Disease Activity Index $(\mathrm{CDAI}) \leq 10$ at week 24 , the investigator was asked to adjust the patient's background RA therapies, and initiation of or change in corticosteroids, nonsteroidal anti-inflammatory drugs, acetaminophen, or csDMARDs was allowed as per the local label. Starting at week 24, at least 20\% improvement in both tender joint count and swollen joint count compared with baseline was required to remain in the study. Any patient who did not fulfill this criterion at 2 consecutive visits was discontinued from the study.

The study was conducted according to the International Conference on Harmonization of Technical Requirements for Pharmaceuticals for Human Use guidelines, applicable regulations and guidelines governing clinical study conduct, and the Declaration of Helsinki. Study-related documents were reviewed and approved by independent ethics committees and institutional review boards. All patients provided written informed consent. The list of Japan study sites is provided in Supplementary Text 1.

\section{Assessments}

American College of Rheumatology (ACR) response rates (ACR20 [primary endpoint for the 12-week, double-blind, treatment period], ACR50, and ACR70), proportions of patients achieving low disease activity (LDA) and remission based on the Disease Activity Score of 28 joints with C-reactive protein (DAS28[CRP]) (LDA $\leq 3.2$ and remission <2.6), CDAI (LDA $\leq 10$ and remission $\leq 2.8$ ), Simplified Disease Activity Index (SDAI) (LDA $\leq 11$ and remission $\leq 3.3$ ), and measures of functional impairment (change from baseline in Health Assessment Questionnaire-Disability Index [HAQ-DI] and morning stiffness severity [numeric rating scale]) were assessed at baseline, weeks 1, 2, 4, 8, 12, 16, 20, 24, and every 12 weeks up to week 84 . The proportion of patients reporting a minimal clinically important improvement in HAQ-DI (decrease from baseline of $\geq$ 0.22 ) was also assessed.

Treatment-emergent adverse events (TEAEs) and clinical laboratory testing that included hematology, chemistry, and urinalysis were recorded during the entire duration of the study. Laboratory data were processed at a central laboratory and categorized according to the Outcome Measures in Rheumatology criteria. For creatine phosphokinase (CPK) and serum creatinine, National Cancer Institute Common Toxicity Criteria (NCI-CTC) were used. Patients were asked to fast for a minimum of $8 \mathrm{~h}$ prior to providing blood samples for laboratory analysis.

\section{Statistical analysis}

The full analysis set, which included all randomized patients who received at least 1 dose of study drug, was used for all efficacy analyses. The safety analysis set, which comprised all patients who received at least 1 
dose of study drug, was used for the long-term safety analysis, with patients who switched from placebo included in their respective upadacitinib groups. Nonresponder imputation was used for binary endpoints, and as-observed data are shown for continuous endpoints. As-observed data for binary endpoints are shown in the Supplementary Information.

\section{Results}

\section{Patients}

Of the 197 Japanese patients randomized in SELECTSUNRISE, 187 (94.9\%) completed 12 weeks on the study drug and entered the blinded extension period (Fig. 1). The cut-off date for this interim analysis was December 26, 2018, when all patients ongoing in the study had completed their week 84 visit. At the cut-off date, 152 (77.2\%) patients were ongoing in period 2. More patients in the upadacitinib $30 \mathrm{mg}$ group had withdrawn because of adverse events (AEs) compared with other treatment groups (Fig. 1).

Patient characteristics and baseline demographics were generally balanced across treatment arms (Supplementary Table $1[11])$.

\section{Efficacy outcomes}

As reported previously, upadacitinib (all doses) met the primary endpoint of ACR20 response at week 12 in this population of Japanese patients with RA and an inadequate response to csDMARDs [11]. In patients originally randomized to upadacitinib, ACR20 response rates for patients on continuous upadacitinib (to week 84) generally showed continued improvement or maintenance over time through week 84 (Fig. 2a). In patients who were originally randomized to placebo, improvements in ACR20 response were seen following switch to upadacitinib at week 12 (Fig. 2a). ACR20 response rates at week 84 were $85.7 \%, 77.6 \%$, and $58.0 \%$ for patients continuing upadacitinib $7.5 \mathrm{mg}, 15 \mathrm{mg}$, and $30 \mathrm{mg}$, respectively, and were similar for patients who had switched to upadacitinib at week 12. Comparable trends were demonstrated for ACR50 and ACR70 responses, although the $15 \mathrm{mg}$ and $30 \mathrm{mg}$ doses of upadacitinib were associated with more rapid and numerically higher initial ACR50/70 responses compared with the $7.5 \mathrm{mg}$ dose (Fig. 2b, c). Similar results were seen with as-observed data (Supplementary Figure 2).

Rates of LDA and remission defined by DAS28(CRP), which were achieved over 12 weeks in patients originally randomized to upadacitinib, improved or were

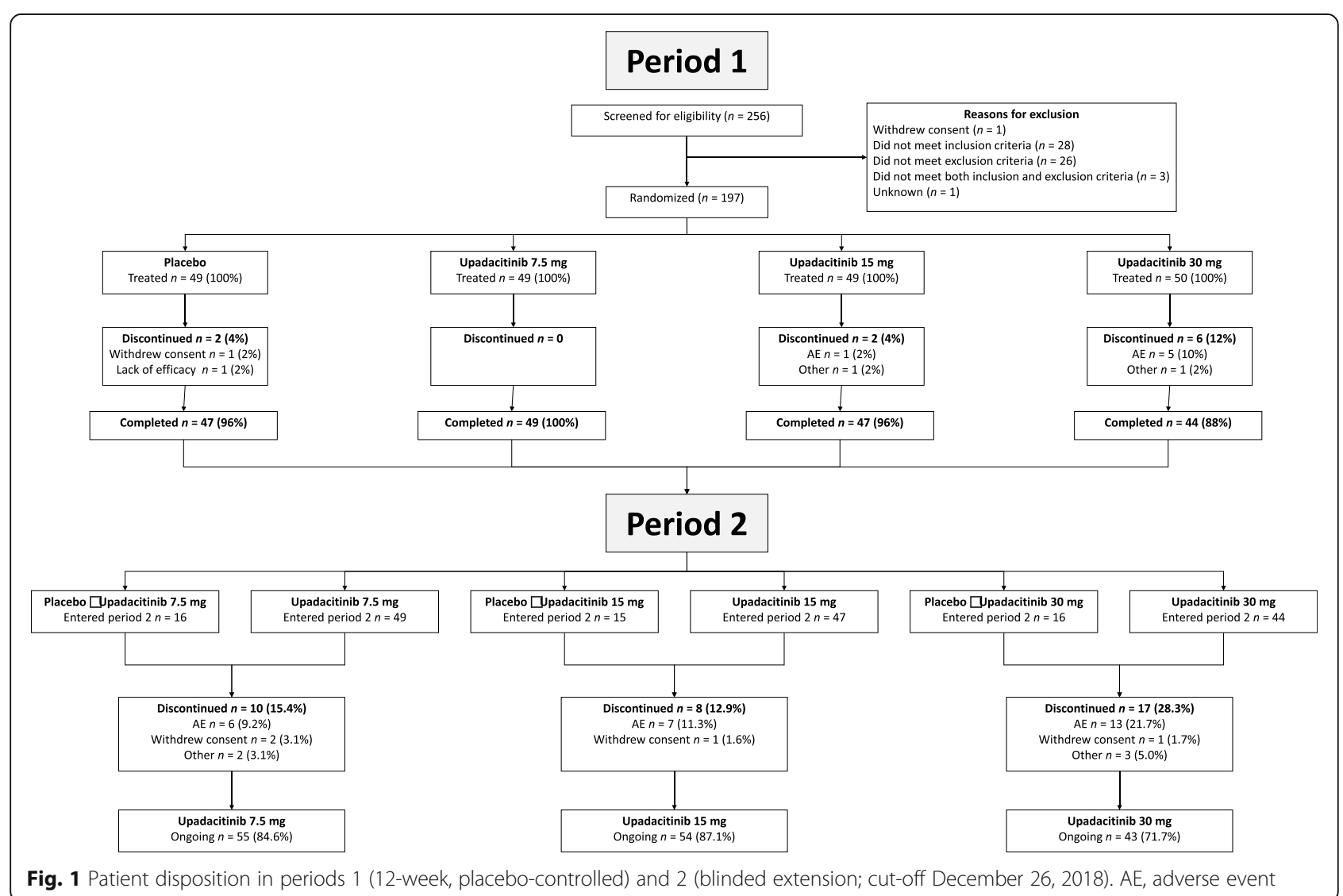




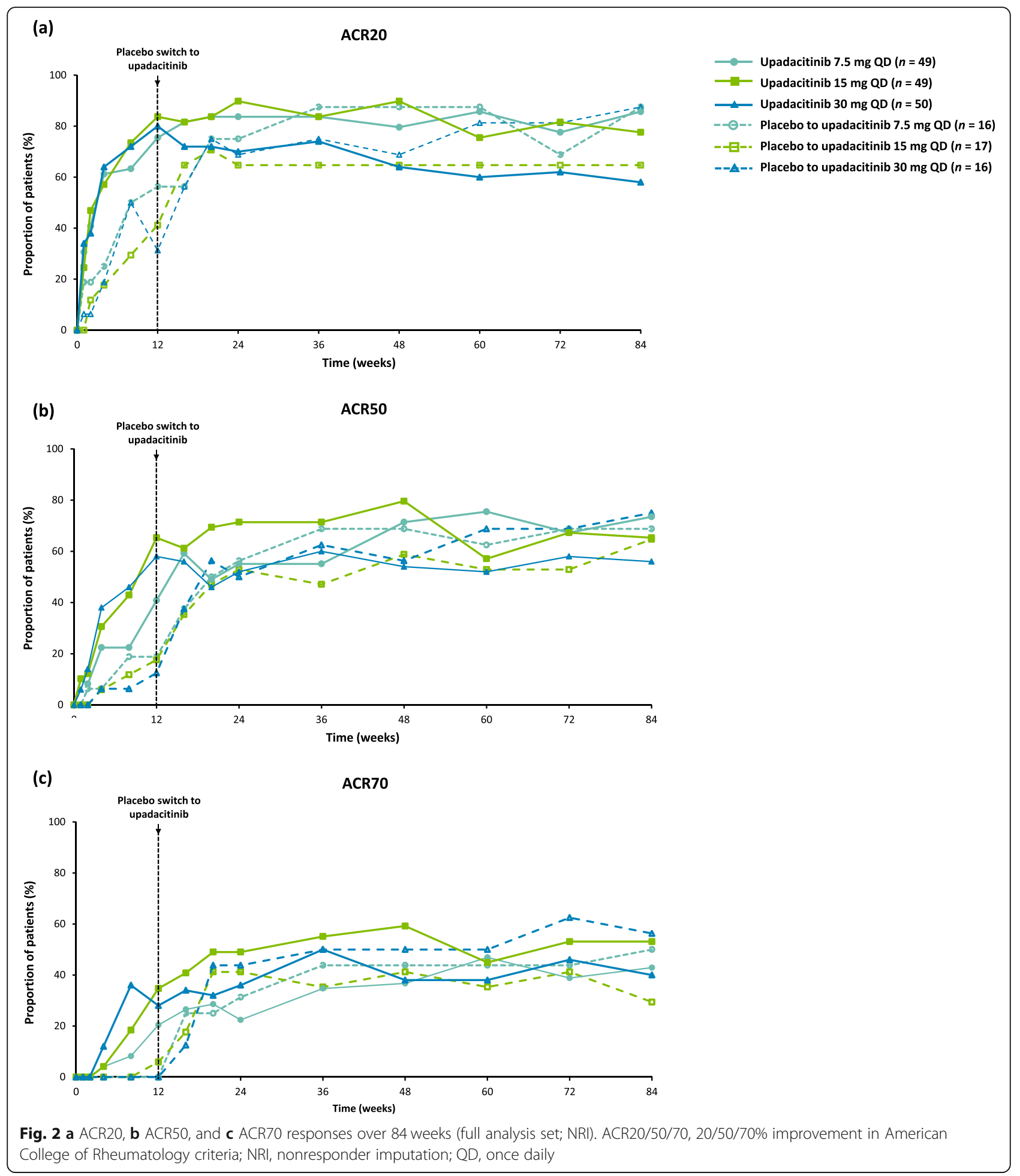

maintained at week 84 (Fig. 3a and b). The proportion of patients achieving these endpoints also improved in patients originally randomized to placebo following switch to upadacitinib at week 12 (Fig. $3 \mathrm{a}$ and b). Comparable trends were demonstrated for rates of LDA and remission defined by CDAI and SDAI (Fig. 3c-f), and were similar with as-observed data (Supplementary Figure 3 ).

The proportion of patients reporting a minimal clinically important improvement in HAQ-DI (decrease from baseline of $\geq 0.22$ ) increased over 84 weeks with upadacitinib (Fig. 4), with similar results using as-observed data 


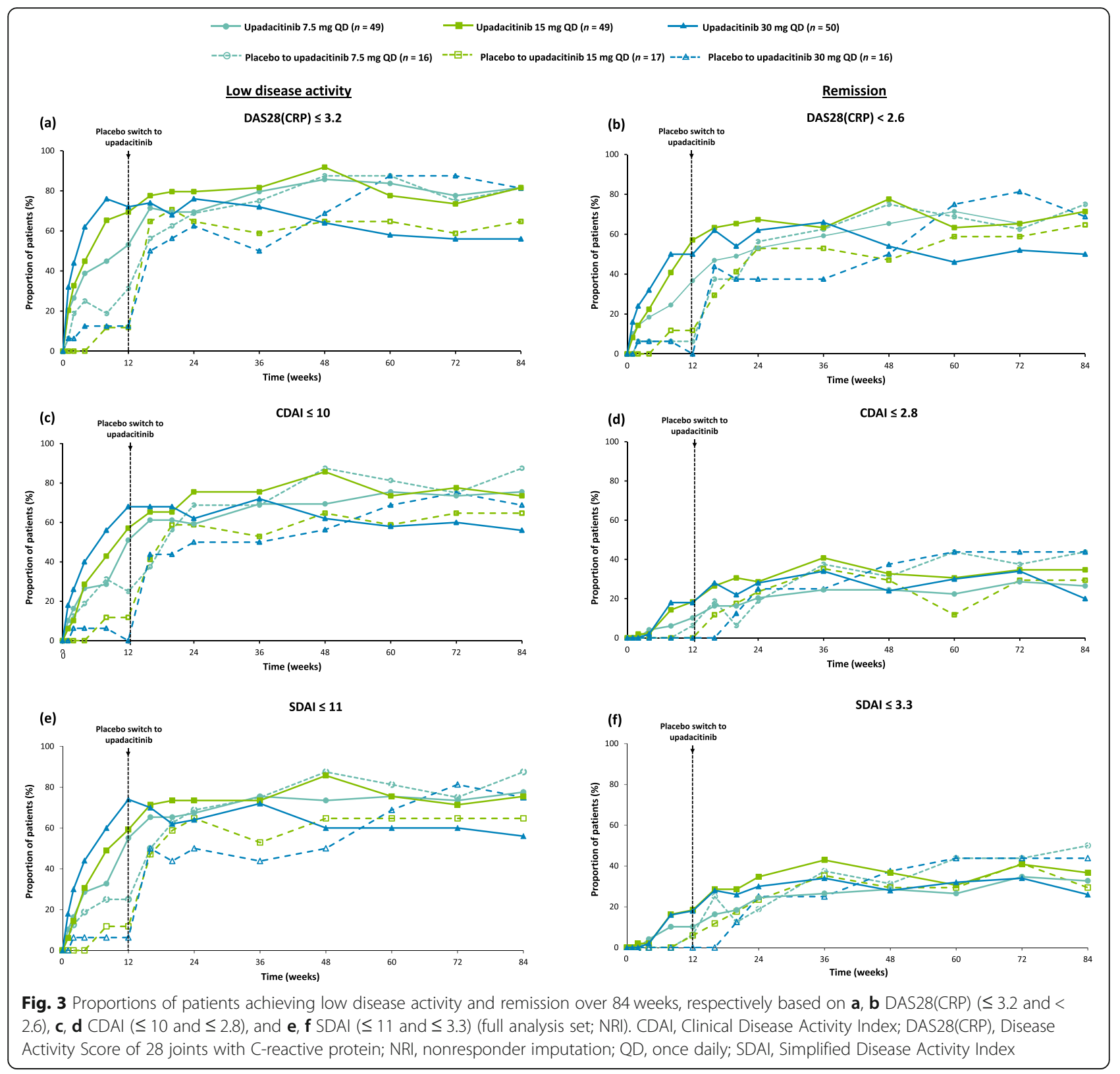

(Supplementary Figure 4a). Improvements were also seen in change from baseline in HAQ-DI and severity of morning stiffness, although smaller improvements were observed in patients who switched from placebo to upadacitinib $7.5 \mathrm{mg}$ compared with those in other treatment groups (Supplementary Figure 4b, c).

\section{Safety}

The rate of overall TEAEs, serious TEAEs, and TEAEs leading to discontinuation tended to show a numerically dose-dependent increase, with slightly higher rates in the $15 \mathrm{mg}$ group versus the $7.5 \mathrm{mg}$ group, and the highest rates observed in the $30 \mathrm{mg}$ group (Table 1). No deaths were reported in the upadacitinib $7.5 \mathrm{mg}$ or 15 mg groups. Two deaths, including 1 treatment-emergent death and 1 non-treatment-emergent death, were reported in the $30 \mathrm{mg}$ group. The treatment-emergent death occurred on day 384 and was due to respiratory failure in a 65-year-old female who experienced a pneumothorax while taking a bath (adjudicated as a cardiovascular death). The non-treatment-emergent death was due to aortic aneurysm rupture on post-study day 131 in a 66-year-old female; this patient had received the study drug for a total of 14 days which had been discontinued for an event of interstitial pneumonia.

The most frequently reported TEAE was nasopharyngitis. The rates of treatment-emergent serious infections (incidence rates $4.7,6.7$, and 12.7 per 100 patient-years, 


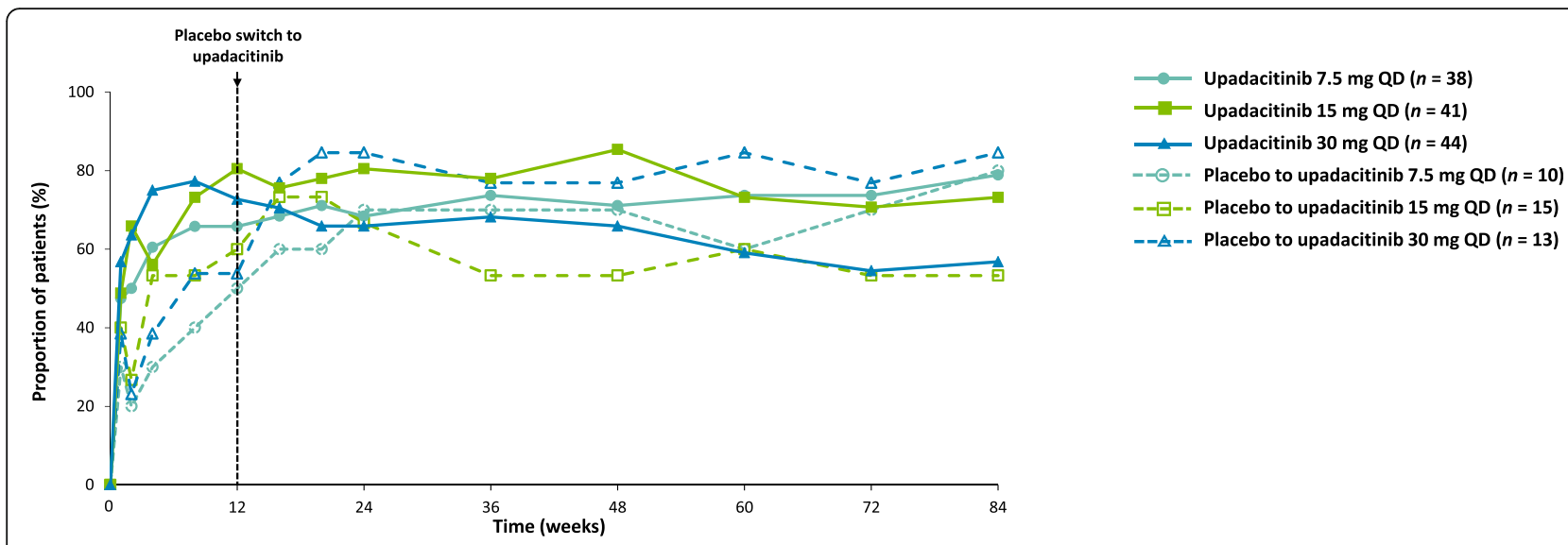

Fig. 4 Proportions of patients reporting minimal clinically important improvement in Health Assessment Questionnaire-Disability Index (HAQ-DI decrease from baseline of $\geq 0.22$ ) over 84 weeks (full analysis set; NRI). NRI, nonresponder imputation; QD, once daily

respectively), opportunistic infections (incidence rates $0.8,3.3$, and 7.6 per 100 patient-years, respectively), and herpes zoster (incidence rates 7.3, 12.3, and 16.5 per 100 patient-years, respectively) appeared to be dose dependent, with lower rates observed with upadacitinib
$7.5 \mathrm{mg}$ and $15 \mathrm{mg}$ versus $30 \mathrm{mg}$ (Table 1 ). The most frequently reported serious infections (with upadacitinib $7.5 \mathrm{mg}, 15 \mathrm{mg}$, and $30 \mathrm{mg}$, respectively) were herpes zoster (incidence rates $2.3,1.7$, and 3.9 per 100 patientyears), pneumonia (incidence rates $1.6,0$, and 2.0 per

Table 1 Summary of treatment-emergent adverse events incidence rate per 100 patient-years in patients who received upadacitinib over 84 weeks (safety analysis set)

\begin{tabular}{|c|c|c|c|}
\hline$\overline{A E}$, incidence (n/100 PY) & $\begin{array}{l}\text { Upadacitinib } 7.5 \mathrm{mg} \\
\text { QD }(n=65)\end{array}$ & $\begin{array}{l}\text { Upadacitinib } 15 \mathrm{mg} \\
\mathrm{QD}(n=64)\end{array}$ & $\begin{array}{l}\text { Upadacitinib } 30 \mathrm{mg} \\
\text { QD }(n=66)\end{array}$ \\
\hline$\overline{\mathrm{AES}}$ & $64(316.8)$ & $64(369.9)$ & $66(458.3)$ \\
\hline Serious AEs & $13(10.8)$ & $17(15.3)$ & $20(20.3)$ \\
\hline $\begin{array}{l}\text { AEs leading to discontinuation } \\
\text { of study drug }\end{array}$ & $6(4.6)$ & $8(6.4)$ & $20(18.6)$ \\
\hline Deaths ${ }^{\dagger}$ & 0 & 0 & $2(1.8)$ \\
\hline Infection & $52(117.1)$ & $57(140.0)$ & $58(167.1)$ \\
\hline Serious infection & $6(4.7)$ & $8(6.7)$ & $13(12.7)$ \\
\hline Opportunistic infection & $1(0.8)$ & $4(3.3)$ & $8(7.6)$ \\
\hline Herpes zoster & $9(7.3)$ & $14(12.3)$ & $16(16.5)$ \\
\hline Active/latent tuberculosis & 0 & 0 & $1(0.9)$ \\
\hline Malignancy (incl. NMSC) & 0 & $1(0.8)$ & $1(0.9)$ \\
\hline Hepatic disorder & $7(5.8)$ & $7(6.1)$ & $8(8.1)$ \\
\hline Gastrointestinal perforation & 0 & $1(0.8)$ & $1(0.9)$ \\
\hline $\mathrm{MACE}^{\ddagger}$ & $1(0.8)$ & 0 & $1(0.9)$ \\
\hline Adjudicated VTE & 0 & 0 & $1(0.9)$ \\
\hline Anemia & 0 & $2(1.6)$ & $5(4.9)$ \\
\hline Neutropenia & $1(0.8)$ & $2(1.7)$ & $7(7.1)$ \\
\hline Lymphopenia & $5(3.9)$ & $7(5.9)$ & $8(7.8)$ \\
\hline CPK elevation & $5(4.0)$ & $7(6.1)$ & $8(8.2)$ \\
\hline Renal dysfunction & 0 & 0 & $1(0.9)$ \\
\hline
\end{tabular}

Two subjects treated with placebo in period 1 discontinued treatment and thus were not included in the safety analysis set

$A E$ adverse event, CPK creatine phosphokinase, MACE, major adverse cardiovascular event, NMSC nonmelanoma skin cancer, $P Y$ patient-years, $Q D$ once daily, VTE, venous thromboembolism

${ }^{\dagger}$ Includes non-treatment-emergent deaths

${ }^{\ddagger}$ Defined as cardiovascular death, nonfatal myocardial infarction, and nonfatal stroke 
100 patient-years), and Pneumocystis jirovecii pneumonia (incidence rates 0,0 , and 3.9 per 100 patient-years). Pneumocystis jirovecii pneumonia, only observed in the upadacitinib $30 \mathrm{mg}$ group (4 events), was the most commonly reported opportunistic infection. The majority of the herpes zoster events were nonserious and involved only 1 dermatome. Serious herpes zoster events included 3 events in the upadacitinib $7.5 \mathrm{mg}$ group, 2 events in the upadacitinib $15 \mathrm{mg}$ group, and 4 events in the upadacitinib $30 \mathrm{mg}$ group. No herpes zoster event was reported as having central nervous system involvement, and there was 1 case of serious herpes zoster with ophthalmic involvement in the $30 \mathrm{mg}$ group. Six patients (3 each in the $15 \mathrm{mg}$ and $30 \mathrm{mg}$ groups, incidence rates 2.4 and 2.8 per 100 patient-years, respectively) reported disseminated herpes zoster infection (3 serious, 3 nonserious), including 5 disseminated cutaneous herpes zoster events and 1 disseminated noncutaneous herpes zoster event in the oral cavity. Of patients with an event of herpes zoster, none had a herpes zoster vaccination prior to baseline (herpes zoster vaccination prior to baseline was unknown for 2 subjects), 28 (71.8\%) were $\geq 50$ years of age, and $3(7.7 \%)$ had a prior history of herpes zoster. There was no active tuberculosis reported.

Two malignancies were reported: acute lymphocytic leukemia in the upadacitinib $15 \mathrm{mg}$ group and Hodgkin disease in the upadacitinib $30 \mathrm{mg}$ group. The subject with acute lymphocytic leukemia was taking concomitant methotrexate and no particular risk factor was identified for the subject with Hodgkin disease. Two patients had TEAEs of gastrointestinal perforation (1 patient with intestinal perforation in the $15 \mathrm{mg}$ group and 1 with events of anal fistula and perirectal abscess in the $30 \mathrm{mg}$ group). Four adjudicated cardiovascular events were reported: 2 major adverse cardiovascular events (respiratory failure adjudicated to cardiovascular death with upadacitinib $30 \mathrm{mg}$, and cerebral infarction adjudicated as a nonfatal stroke with upadacitinib $7.5 \mathrm{mg}$ ), 1 transient ischemic attack (upadacitinib $7.5 \mathrm{mg}$ ), and 1 deep vein thrombosis (upadacitinib $30 \mathrm{mg}$ ). All patients, except for the patient with respiratory failure, had cardiovascular risk factors at study entry. With the exception of deep vein thrombosis, all events were reported as serious TEAEs and as having a reasonable possibility of being related to the study drug.

Rates of neutropenia, lymphopenia, anemia, and CPK elevation appeared to be dose dependent; rates were slightly higher in the $15 \mathrm{mg}$ group versus the $7.5 \mathrm{mg}$ group and were highest in the $30 \mathrm{mg}$ group (Table 1). No patient discontinued the study drug due to a TEAE of anemia or neutropenia. Two patients, both receiving upadacitinib 30 $\mathrm{mg}$, had TEAEs of lymphopenia that led to discontinuation of the study drug. One patient receiving upadacitinib $15 \mathrm{mg}$ discontinued the study drug due to an asymptomatic TEAE of CPK elevation. No patient had rhabdomyolysis. The rate of hepatic disorders was comparable across the doses, and renal dysfunction was uncommon.

The proportion of patients with grade 3 decreases in hemoglobin and lymphocyte levels was higher with upadacitinib $30 \mathrm{mg}$ compared with the other doses (Table 2). However, over half of patients randomized to upadacitinib treatment had grade 2 or 3 lymphocyte counts at baseline, with the highest rates in the upadacitinib $30 \mathrm{mg}$ group (Table 3). Of the grade 3 or 4 decreases in hemoglobin, none led to study drug discontinuation, and approximately half were isolated events, occurring at only 1 time point during the treatment period. Of $10 \mathrm{pa}-$ tients with grade 4 lymphocyte decreases, 3 discontinued the study drug and 3 had infectious events ( 1 event each of pneumonia, infectious enteritis, and Pneumocystis jirovecii pneumonia) around the onset of lymphopenia (approximately -16 to 5 days). Grade 3 or 4 changes in neutrophils, leukocytes, alanine aminotransferase (ALT), aspartate aminotransferase (AST), and CPK were rare. Increases in ALT and AST were mostly isolated events, and all returned to normal during the treatment period. One patient (upadacitinib $7.5 \mathrm{mg}$ ) had a grade 4 decrease in neutrophil levels; this patient had nasopharyngitis around the time of neutropenia and did not discontinue the study drug due to a decreased neutrophil count. One patient who received upadacitinib $15 \mathrm{mg}$ discontinued the study drug during the study follow-up period due to an asymptomatic increase in blood CPK. No patient had a grade 3 or 4 increase in serum creatinine.

\section{Discussion}

The SELECT-SUNRISE study assessed the efficacy and safety profile of 3 doses of upadacitinib $(7.5 \mathrm{mg}, 15 \mathrm{mg}$, and $30 \mathrm{mg}$ ) in Japanese patients who had moderately to severely active RA despite a stable dose of csDMARDs. In the 12-week study, upadacitinib showed consistent improvement in clinical and patient-reported outcomes versus placebo across all 3 doses. These improvements increased or were maintained through to week 84 in the long-term extension in patients who were originally randomized to upadacitinib. In addition, patients who switched from placebo to upadacitinib at week 12 showed efficacy improvements up to week 84 similar to those observed for patients originally randomized to upadacitinib. This suggests that upadacitinib may be a favorable long-term option for Japanese patients with RA who have an inadequate response to csDMARDs.

Long-term efficacy was generally comparable across the 3 doses, although the $15 \mathrm{mg}$ and $30 \mathrm{mg}$ doses were associated with more rapid and overall numerically higher initial responses for more stringent measures of 
Table 2 Patients with worsening in grade severity (grades 3 or 4) for laboratory parameters at any time during 84 weeks, including single isolated values (safety analysis set)

\begin{tabular}{|c|c|c|c|}
\hline Lab parameter $^{\dagger} n(\%)$ & $\begin{array}{l}\text { Upadacitinib } 7.5 \mathrm{mg} \\
\text { QD }(n=65)\end{array}$ & $\begin{array}{l}\text { Upadacitinib } 15 \mathrm{mg} \\
\text { QD }(n=64)\end{array}$ & $\begin{array}{l}\text { Upadacitinib } 30 \mathrm{mg} \\
\text { QD }(n=66)\end{array}$ \\
\hline \multicolumn{4}{|l|}{ Hemoglobin (g/L) } \\
\hline Grade 3 (70 to $<80$ or $\downarrow 21$ to $<30$ ) & 0 & $1(1.6)$ & $9(13.6)$ \\
\hline Grade $4(<70$ or $\downarrow \geq 30)$ & $1(1.5)$ & 0 & $4(6.1)$ \\
\hline \multicolumn{4}{|l|}{ Lymphocytes $\left(\times 10^{9} / \mathrm{L}\right)$} \\
\hline Grade $3(0.5$ to $<1.0)$ & $30(46.2)$ & $27(42.2)$ & $36(54.5)$ \\
\hline Grade $4(<0.5)$ & $4(6.2)$ & $2(3.1)$ & $4(6.1)$ \\
\hline \multicolumn{4}{|l|}{ Neutrophils $\left(\times 10^{9} / \mathrm{L}\right)$} \\
\hline Grade $3(0.5$ to < 1.0$)$ & $1(1.5)$ & $1(1.6)$ & $2(3.0)$ \\
\hline Grade $4(<0.5)$ & $1(1.5)$ & 0 & 0 \\
\hline \multicolumn{4}{|l|}{ Leukocytes $\left(\times 10^{9} / L\right)$} \\
\hline Grade 3 (1.0 to < 2.0) & $1(1.5)$ & 0 & $1(1.5)$ \\
\hline Grade $4(<1.0)$ & 0 & 0 & 0 \\
\hline \multicolumn{4}{|l|}{$\mathrm{ALT}(\mathrm{U} / \mathrm{L})$} \\
\hline Grade $3(3.0-8.0 \times$ ULN) & $1(1.5)$ & $3(4.7)$ & $2(3.0)$ \\
\hline Grade $4(>8.0 \times$ ULN) & 0 & 0 & $1(1.5)$ \\
\hline \multicolumn{4}{|l|}{ AST (U/L) } \\
\hline Grade $3(3.0-8.0 \times$ ULN) & $1(1.5)$ & $2(3.1)$ & $2(3.0)$ \\
\hline Grade 4 (> $8.0 \times$ ULN) & 0 & 0 & 0 \\
\hline \multicolumn{4}{|l|}{ CPK (U/L) } \\
\hline Grade 3 (> 5-10× ULN) & $2(3.1)$ & $2(3.1)$ & $3(4.5)$ \\
\hline Grade 4 (> $10 \times$ ULN) & 0 & $1(1.6)$ & $4(6.1)$ \\
\hline \multicolumn{4}{|l|}{ Creatinine $(\mu \mathrm{mol} / \mathrm{L})$} \\
\hline Grade 3 (> 3.0-6.0 × ULN) & 0 & 0 & 0 \\
\hline Grade 4 (> $6.0 \times$ ULN) & 0 & 0 & 0 \\
\hline
\end{tabular}

Two subjects treated with placebo in period 1 discontinued treatment and thus were not included in the safety analysis set. Notes: For CPK and creatinine, NCICTC criteria were used. Post-baseline grade must be higher than the baseline grade

ALT alanine aminotransferase, AST aspartate aminotransferase, CPK creatine phosphokinase, NCI-CTC National Cancer Institute Common Toxicity Criteria, OMERACT Outcome Measures in Rheumatology, QD once daily, ULN upper limit of normal

${ }^{+}$The toxicity grading is based on OMERACT criteria (Rheumatology Common Toxicity Criteria v.2.0)

response (ACR70) and remission (defined by DAS28[CRP], CDAI, SDAI) compared with the $7.5 \mathrm{mg}$ dose. A similar trend was observed in physical function (HAQ-DI; weeks 12-84) between groups switching from placebo. For all efficacy outcomes measured, the $30 \mathrm{mg}$ dose provided no additional benefit compared with the $15 \mathrm{mg}$ dose, suggesting that the $15 \mathrm{mg}$ dose was associated with optimal efficacy. These results are consistent with the SELECT-EARLY Japanese subanalysis, in which significant improvements were observed across primary (including radiographic) and secondary endpoints with upadacitinib $15 \mathrm{mg}$ and $30 \mathrm{mg}$

Table 3 Lymphocyte count as baseline (safety analysis set)

\begin{tabular}{|c|c|c|c|}
\hline Lymphocytes $^{\dagger}, \times 10^{9} / L, n(\%)$ & $\begin{array}{l}\text { Upadacitinib } 7.5 \mathrm{mg} \\
\mathrm{QD}(n=65)\end{array}$ & $\begin{array}{l}\text { Upadacitinib } 15 \mathrm{mg} \\
\mathrm{QD}(n=64)\end{array}$ & $\begin{array}{l}\text { Upadacitinib } 30 \mathrm{mg} \\
\text { QD }(n=66)\end{array}$ \\
\hline Grade $0(>2.0)$ & $5(7.7)$ & $9(14.1)$ & $7(10.6)$ \\
\hline Grade $1(1.5$ to $<2.0)$ & $21(32.3)$ & $11(17.2)$ & $11(16.7)$ \\
\hline Grade $2(1.0$ to $<1.5)$ & $33(50.8)$ & $31(48.4)$ & $37(56.1)$ \\
\hline Grade $3(0.5$ to $<1.0)$ & $6(9.2)$ & $13(20.3)$ & $11(16.7)$ \\
\hline
\end{tabular}

Two subjects treated with placebo in period 1 discontinued treatment and thus were not included in the safety analysis set $Q D$ once daily

${ }^{\dagger}$ The toxicity grading is based on Outcome Measures in Rheumatology criteria (Rheumatology Common Toxicity Criteria v.2.0) 
monotherapy versus methotrexate in methotrexatenaïve patients, with no additional benefits with the 30 $\mathrm{mg}$ dose, while the $7.5 \mathrm{mg}$ dose led to significant improvements in the nonradiographic primary endpoint (ACR20) and secondary endpoints only [19].

Similar to the 12-week data [11], long-term safety data tended to show numerically dose-dependent increases in incidence rates of AEs, including serious AEs, serious infection, herpes zoster, and AEs leading to discontinuation of the study drug. Due to the small sample size, these data should be interpreted with caution.

Both the $7.5 \mathrm{mg}$ and $15 \mathrm{mg}$ doses of upadacitinib have been approved for the treatment of RA in Japan; however, efficacy and safety results from this study indicate upadacitinib $15 \mathrm{mg}$ as the optimal dose for long-term treatment in these patients. Findings are consistent with the SELECTEARLY Japanese sub-analysis, in which upadacitinib $15 \mathrm{mg}$ was identified as the optimal dose versus the $7.5 \mathrm{mg}$ and 30 $\mathrm{mg}$ doses. Of note, the efficacy and safety profile of upadacitinib in this study were broadly similar to those reported in global trials of upadacitinib; however, rates of herpes zoster were higher in this study versus global trials [15-18]. Higher rates of herpes zoster have similarly been reported in Japanese and Korean patients treated with baricitinib and tofacitinib compared with other geographical regions, although the reasons for this are unclear [9]. Similar to the overall rate of herpes zoster, the incidence of disseminated herpes zoster ( 3 cases each in the $15 \mathrm{mg}$ and $30 \mathrm{mg}$ groups, incidence rates 2.4 and 2.8 per 100 patient-years, respectively) tended to be numerically higher in this study compared with a global population (incidence rate $<0.1$ per 100 patient-years with upadacitinib $15 \mathrm{mg}$ [data on file]).

This study has several limitations, in common with all long-term studies. Efficacy data should be interpreted with caution, as there was no placebo comparison from week 12 onwards (although blinding was maintained) and no statistical comparisons were performed between upadacitinib treatment groups. Finally, changes in background medication were permitted from week 24 onwards, which may confound the efficacy and safety findings with upadacitinib.

\section{Conclusions}

Overall, results demonstrate that upadacitinib is an efficacious and well-tolerated treatment option for Japanese patients with RA and an inadequate response to csDMARDs. Upadacitinib at the $15 \mathrm{mg}$ dose showed the most favorable long-term benefit-risk profile in this Japanese population.

\section{Supplementary Information}

The online version contains supplementary material available at https://doi. org/10.1186/s13075-020-02387-6

Additional file 1. Supplementary Figure 1.
Additional file 2. Supplementary Text 1.

Additional file 3. Supplementary Table 1

Additional file 4. Supplementary Figure 2.

Additional file 5. Supplementary Figure 3.

Additional file 6. Supplementary Figure 4.

\section{Abbreviations}

ACR20/50/70: 20\%/50\%/70\% improvement in American College of Rheumatology criteria; AE: Adverse event; ALT: Alanine transaminase; AST: Aspartate transaminase; bDMARD: Biologic disease-modifying antirheumatic drug; CDAl: Clinical Disease Activity Index; CPK: Creatine phosphokinase; csDMARD: Conventional synthetic disease-modifying antirheumatic drug; DAS28(CRP): Disease Activity Score of 28 joints with Creactive protein; HAQ-DI: Health Assessment Questionnaire-Disability Index; JAK: Janus kinase; LDA: Low disease activity; MACE: Major adverse cardiovascular event; NMSC: Nonmelanoma skin cancer; NCI-CTC: National Cancer Institute Common Toxicity Criteria; NRI: Nonresponder imputation; OMERACT: Outcome Measures in Rheumatology; QD: Once daily;

RA: Rheumatoid arthritis; SDAl: Simplified Disease Activity Index;

TEAE: Treatment-emergent adverse event; TYK2: Tyrosine kinase 2;

ULN: Upper limit of normal; VTE: Venous thromboembolism

\section{Acknowledgments}

AbbVie funded this study and participated in the study design, research, analysis, data collection, interpretation of data, reviewing, and approval of the publication. All authors had access to relevant data and participated in the drafting, review, and approval of this publication. No honoraria or payments were made for authorship. Medical writing support was provided by John Ewbank, PhD, and Frances Smith, PhD, of 2 the Nth (Cheshire, UK) and was funded by AbbVie.

\section{Authors' contributions}

All authors contributed to the study concept/design, data acquisition, analysis, and interpretation, as well as drafting of the manuscript and revising it critically for important intellectual content. All authors provided final approval of the version to be published.

\section{Funding}

AbbVie funded this study and participated in the study design, research, analysis, data collection, interpretation of data, reviewing, and approval of the publication. No honoraria or payments were made for authorship.

\section{Availability of data and materials}

These clinical trial data can be requested by any qualified researchers who engage in rigorous, independent scientific research, and will be provided following review and approval of a research proposal and Statistical Analysis Plan (SAP) and execution of a Data Sharing Agreement (DSA). Data requests can be submitted at any time and the data will be accessible for 12 months, with possible extensions considered. For more information on the process, or to submit a request, visit the following link: https://www.abbvie.com/ourscience/clinical-trials/clinical-trials-data-and-information-sharing/data-andinformation-sharing-with-qualified-researchers.html.

\section{Ethics approval and consent to participate}

The study was conducted according to the International Conference on Harmonization of Technical Requirements for Pharmaceuticals for Human Use guidelines, applicable regulations and guidelines governing clinical study conduct, and the Declaration of Helsinki. Study-related documents were reviewed and approved by independent ethics committees and institutional review boards. All patients provided written informed consent.

\section{Consent for publication}

Not applicable.

\section{Competing interests}

Hideto Kameda: Consulting fees, speaking fees, and/or honoraria: AbbVie GK, Asahi-Kasei, Bristol-Myers Squibb, Chugai, Eli Lilly Japan K.K., Gilead, Janssen K.K., Mitsubishi-Tanabe, Novartis, Pfizer Japan, Sanofi K.K., and UCB Japan. 
Research grants: AbbVie GK, Asahi-Kasei, Astellas, Chugai, Eisai, MitsubishiTanabe, and Novartis.

Tsutomu Takeuchi: Personal fees: AbbVie GK, Astellas, AYUMI, Bristol-Myers Squibb K.K., Boehringer-Ingelheim, Chugai, Daiichi-Sankyo, Eisai, Eli Lilly Japan K.K., Gilead, GlaxoSmithKline K.K., Janssen K.K., Mitsubishi-Tanabe, Novartis K.K. Nipponkayaku, Pfizer Japan, Sanofi K.K., Taiho, Taisho, and UCB Japan. Grants: AbbVie GK, Asahi-Kasei, Astellas, AYUMI, Chugai, Daiichi-Sankyo, Eisai, Mitsubishi-Tanabe, Nipponkayaku, Novartis K.K., Pfizer Japan, Shionogi \& Co., and Takeda. Speaker fees: AbbVie GK, Astellas, AYUMI, Chugai, Daiichi-Sankyo, Eisai, Gilead, Mitsubishi-Tanabe, Novartis K.K., Pfizer Japan, Sanofi K.K., Takeda, and Teijin. Consultant fees: Astellas, Boehringer-Ingelheim, Chugai, Janssen K.K., Mitsubishi-Tanabe, Nipponkayaku, Taiho, Taisho Toyama, and UCB Japan. Kunihiro Yamaoka: Speakers bureau: AbbVie GK, Astellas, Bristol-Myers Squibb, Chugai, Mitsubishi-Tanabe, Pfizer Japan, and Takeda.

Motohiro Oribe and Mitsuhiro Kawano: None declared.

Masayuki Yokoyama, Aileen L Pangan, Yuko Konishi, and Sebastian Meerwein: Employees of AbbVie and may own stock or options.

Yoshiya Tanaka: Speaking fees and/or honoraria: AbbVie, Astellas, BristolMyers Squibb, Chugai, Daiichi-Sankyo, Eli Lilly, Eisai, Janssen, MitsubishiTanabe, Novartis, Pfizer, Takeda, Teijin, and YL Biologics. Research grants: Asahi-Kasei, Bristol-Myers Squibb, Chugai, Daiichi-Sankyo, Eisai, MitsubishiTanabe, Ono, Sanofi, Takeda, and UCB.

\section{Author details}

${ }^{1}$ Division of Rheumatology, Department of Internal Medicine, Faculty of Medicine, Toho University, 2-22-36, Ohashi, Meguro-ku, Tokyo 153-8515, Japan. ${ }^{2}$ Keio University School of Medicine, 2 Chome-15-45 Mita, Minato City, Tokyo 108-8345, Japan. ${ }^{3}$ Kitasato University School of Medicine, 1

Chome-15-1 Kitazato, Minami Ward, Sagamihara, Kanagawa 252-0374, Japan. ${ }^{4}$ Department of Internal Medicine, Oribe Clinic of Rheumatism and Medicine, Oita Oita-shi Otemachi 2-1-15, Oita, Japan. ${ }^{5}$ Rheumatology, Honjo Rheumatism Clinic, Takaoka, Toyama 933-0874, Japan. ${ }^{6}$ Immunology, AbbVie GK, 16F, 3 Chome-1-14F Shibaura, Minato City, Tokyo 105-0023, Japan. ${ }^{7}$ Immunology, AbbVie, 1400 Sheridan Rd, North Chicago, IL 60064, USA ${ }^{8}$ Pharmaceutical Development, AbbVie Deutschland GmbH \& Co KG, Knollstraße 50, 67061 Ludwigshafen am Rhein, Germany. ${ }^{9}$ The First Department of Internal Medicine, University of Occupational and Environmental Health, 1-1 Iseigaoka, Yahatanishi Ward, Kitakyushu, Fukuoka 807-8555, Japan

Received: 21 July 2020 Accepted: 7 December 2020

Published online: 06 January 2021

\section{References}

1. Alunno A, Padjen I, Fanouriakis A, Boumpas DT. Pathogenic and therapeutic relevance of JAK/STAT signaling in systemic lupus erythematosus: integration of distinct inflammatory pathways and the prospect of their inhibition with an oral agent. Cells. 2019:8(8):898.

2. Mclnnes IB, Schett $G$. Pathogenetic insights from the treatment of rheumatoid arthritis. Lancet. 2017;389(10086):2328-37.

3. O'Shea J, Kontzias A, Yamaoka K, Tanaka Y, Laurence A. Janus kinase inhibitors in autoimmune diseases. Ann Rheum Dis. 2013;72(Suppl 2): ii $111-5$.

4. Kameda H, Fujii T, Nakajima A, Koike R, Sagawa A, Kanbe K, et al. Japan College of Rheumatology guideline for the use of methotrexate in patients with rheumatoid arthritis. Mod Rheumatol. 2019;29(1):31-40.

5. Singh JA, Saag KG, Bridges SL Jr, Akl EA, Bannuru RR, Sullivan MC, et al. 2015 American College of Rheumatology guideline for the treatment of rheumatoid arthritis. Arthritis Rheumatol. 2016:68(1):1-26.

6. Smolen JS, Landewe RBM, Bijlsma JWJ, Burmester GR, Dougados M, Kerschbaumer A, et al. EULAR recommendations for the management of rheumatoid arthritis with synthetic and biological disease-modifying antirheumatic drugs: 2019 update. Ann Rheum Dis. 2020;79(6):685-99.

7. Taylor PC. Clinical efficacy of launched JAK inhibitors in rheumatoid arthritis. Rheumatology (Oxford). 2019;58(Suppl 1):i17-26.

8. Harigai M. Growing evidence of the safety of JAK inhibitors in patients with rheumatoid arthritis. Rheumatology (Oxford). 2019;58(Suppl 1):i34-42.

9. Tanaka Y, Ishii T, Cai Z, Schlichting D, Rooney T, Macias W. Efficacy and safety of baricitinib in Japanese patients with active rheumatoid arthritis: a 52-week, randomized, single-blind, extension study. Mod Rheumatol. 2018; 28(1):20-9.
10. Yamanaka H, Tanaka Y, Takeuchi T, Sugiyama N, Yuasa H, Toyoizumi S, et al. Tofacitinib, an oral Janus kinase inhibitor, as monotherapy or with background methotrexate, in Japanese patients with rheumatoid arthritis: an open-label, long-term extension study. Arthritis Res Ther. 2016;18:34.

11. Kameda H, Takeuchi T, Yamaoka K, Oribe M, Kawano M, Zhou Y, et al. Efficacy and safety of upadacitinib in Japanese patients with rheumatoid arthritis (SELECT-SUNRISE): a placebo-controlled phase Ilb/III study. Rheumatology (Oxford) 2020:[Epub ahead of print].

12. Summary of treatment-emergent adverse. 2018;2:23.

13. Genovese MC, Smolen JS, Weinblatt ME, Burmester GR, Meerwein S, Camp HS, et al. Efficacy and safety of ABT-494, a selective JAK-1 inhibitor, in a phase IIb study in patients with rheumatoid arthritis and an inadequate response to methotrexate. Arthritis Rheumatol. 2016;68(12):2857-66.

14. Kremer JM, Emery P, Camp HS, Friedman A, Wang L, Othman AA, et al. A phase Ilb study of ABT-494, a selective JAK-1 inhibitor, in patients with rheumatoid arthritis and an inadequate response to anti-tumor necrosis factor therapy. Arthritis Rheumatol. 2016;68(12):2867-77.

15. Burmester GR, Kremer JM, Van den Bosch F, Kivitz A, Bessette L, Li Y, et al. Safety and efficacy of upadacitinib in patients with rheumatoid arthritis and inadequate response to conventional synthetic disease-modifying antirheumatic drugs (SELECT-NEXT): a randomised, double-blind, placebocontrolled phase 3 trial. Lancet. 2018:391(10139):2503-12.

16. Fleischmann $\mathrm{R}$, Pangan $\mathrm{AL}$, Song $\mathbb{H}_{\text {, Mysler }}$, Bessette $L$, Peterfy $C$, et al. Upadacitinib versus placebo or adalimumab in patients with rheumatoid arthritis and an inadequate response to methotrexate: results of a phase III, double-blind, randomized controlled trial. Arthritis Rheumatol. 2019;71(11): 1788-800

17. Genovese MC, Fleischmann R, Combe B, Hall S, Rubbert-Roth A, Zhang Y, et al. Safety and efficacy of upadacitinib in patients with active rheumatoid arthritis refractory to biologic disease-modifying anti-rheumatic drugs (SELE CT-BEYOND): a double-blind, randomised controlled phase 3 trial. Lancet. 2018;391(10139):2513-24

18. Smolen JS, Pangan AL, Emery P, Rigby W, Tanaka Y, Vargas Jl, et al. Upadacitinib as monotherapy in patients with active rheumatoid arthritis and inadequate response to methotrexate (SELECT-MONOTHERAPY): a randomised, placebo-controlled, double-blind phase 3 study. Lancet. 2019; 393(10188):2303-11.

19. Takeuchi T, van Vollenhoven R, Pangan AL, Friedman A, Mohamed ME, Chen S, et al. A phase 3, randomized controlled trial comparing upadacitinib monotherapy to MTX monotherapy in MTX-naïve patients with active rheumatoid arthritis [Abstract W38-2]. Mod Rheumatol. 2019;29:S118.

\section{Publisher's Note}

Springer Nature remains neutral with regard to jurisdictional claims in published maps and institutional affiliations.

\section{Ready to submit your research? Choose BMC and benefit from:}

- fast, convenient online submission

- thorough peer review by experienced researchers in your field

- rapid publication on acceptance

- support for research data, including large and complex data types

- gold Open Access which fosters wider collaboration and increased citations

- maximum visibility for your research: over $100 \mathrm{M}$ website views per year

At $\mathrm{BMC}$, research is always in progress.

Learn more biomedcentral.com/submissions 